\title{
Sobre el tema de las estrategias didácticas en los trabajos especiales de grado
}

\section{Didactic Strategies in Special Graduate Projects}

\author{
Marcel Alejandro Doubront-Guerrero \\ Universidad Nacional Experimental Simón Rodríguez \\ Venezuela \\ marceldoubront@gmail.com \\ Luis Gerardo Doubront-Guerrero \\ Universidad Nacional Experimental Simón Rodríguez \\ Venezuela \\ dr.doubront@gmail.com \\ https://orcid.org/0000-0003-4174-2169
}

Recibido: $13 / 05 / 2020 \cdot$ Aceptado:01/09/2020

Resumen. El presente artículo es una reflexión sobre cómo se alejan los trabajos especiales de grado del contexto humanista, promoviendo el humanismo, es decir, una humanización de la educación, sin tomar como referencia al ser humano, sino a las estrategias didácticas, desconociendo quién las aplica y los factores que se adicionan a su aplicación. En tal sentido, se hace un abordaje referente no solo a la finalidad de la educación sino a la teoría de las emociones planteadas por Maslow, con el fin de conocer, comprender y determinar cómo piensan las y los docentes y cuál sería la alternativa más oportuna en beneficio de la educación y sus estudiantes.

Palabras clave: educación, docente, estudiante, estrategias didácticas, Maslow.

Abstract. This article is a reflection on how special graduate projects move away from the humanist context, promoting humanism, that is, a humanization of education without taking the human as a reference but the didactic strategies, ignoring who applies them and the factors involved in their application. In this sense, an approach is made referring not only to the purpose of education but also to Maslow's theory of emotions in order to know, understand, and determine how and why teachers think, and also, what the most appropriate alternative should benefit education and its students.

Keywords: education, teacher, educating, didactic strategies, Maslow. 
Revista Universidad en Diálogo • Vol. 11, N. ${ }^{\circ}$ 1, Enero-Junio, 2021 • 11-35

ISSN 2215-2849 • EISSN: 2215-4752

URL: http://www.revistas.una.ac.cr/index.php/dialogo/index CORREO ELECTRÓNICO: universidadendialogo@una.cr DOI: http://doi.org/10.15359/udre.11-1.1

\section{Introducción}

1 mundo académico de hoy transita por lo que puede llamarse una crisis de pertenencia social: sus contenidos y su praxis son totalmente opuestos a las demandas de la sociedad en el presente histórico; por el contrario, aunque no se pudiera afirmar que es por mala fe, la carencia de emprendimiento hace que se pretenda formar a sujetos sociales del y en el siglo XXI con pénsum del siglo XX y estrategias del siglo XIX, lo que sin duda no solo promueve una descontextualización científica sino social de los y las estudiantes. En relación con lo planteado, la Ley de Universidades de 1970 vigente reza que "las universidades están al servicio de la nación y a ellas corresponde colaborar en la orientación de la vida del país mediante su acción doctrinaria", sin embargo, si en estas no se promueve una educación de pertinencia, poco será el aporte al país.

El presente trabajo tiene la intención de concientizar al personal docente y a la universidad misma sobre el tipo de investigaciones que se están realizando en el campo de la educación. Es de vital importancia entender que la educación es un acto de sujetos, con sujetos y entre sujetos, por ende el ser humano en su ontología no puede ser un dato aislado del problema que se aborde en la investigación, por el contrario, las estrategias educativas que se intenten promover deben tener como centro el reconocimiento para el desarrollo humano y, a su vez, la incidencia de este en los procesos de transformación social, ya que un conocimiento sin conciencia acrecentará más el problema y no edificará ninguna solución de fondo.

Dicho trabajo se estructura desde la teoría crítica, buscando promover transformaciones sociales y promoviendo una alternativa en el contexto educativo con las personas que hacen vida en él; de igual manera, el estudio se enmarca en una visión fenomenológica del desafío expuesto, que analiza ante los procesos de crisis el aspecto ontológico del y de la docente y su praxis profesional.

Por último, se espera que mediante la presente investigación se generen reflexiones colectivas para promover una educación de carácter pertinente, que permita vencer el pensamiento reduccionista y fragmentado de personas docentes y estudiantes investigadoras en aras de que, como plantea Freire, la educación cambie a las personas para cambiar al mundo.

\section{Sobre el tema de las estrategias didácticas en los trabajos especiales de grado}

Uno de los grandes dilemas como persona tutora o siendo jurado de trabajos especiales de grado es encontrarse en muchos proyectos títulos relacionados 
URL: http://www.revistas.una.ac.cr/index.php/dialogo/index

CORREO ELECTRÓNICO: universidadendialogo@una.cr

DOI: http://doi.org/10.15359/udre.11-1.1

con las "estrategias didácticas", lo que sin duda, más que criticar lo recurrente del tema - ya que donde hay una necesidad la persona docente y la persona estudiante investigadora deben ser las primeras en señalarla y plantear su solución-, denota que hay un problema muy significativo referente a cómo se imparte la educación: una educación con visión simplista y epidérmica ante las razones de fondo que adicionan al problema en cuestión. En correspondencia plantea Savater (1997):

El problema educativo ya no puede reducirse sencillamente al fracaso de un puñado de alumnos, por numeroso que sea, ni tampoco a que la escuela no cumpla como es debido las nítidas misiones que la comunidad le encomienda, sino que adopta un perfil previo y más ominoso: el desdibujamiento o la contradicción de esas mismas demandas.

En tal sentido, la educación en términos rasos puede referirse a un proceso de formación que busca la transformación del ser humano y su incidencia en la sociedad, es la oportunidad de forjar humanamente con las personas la sociedad que soñamos. Delors (1994) expresa que "frente a los numerosos desafíos del porvenir, la educación constituye un instrumento indispensable para que la humanidad pueda progresar hacia los ideales de paz, libertad y justicia social". Claramente, la educación es mucho más que enseñar a leer, ya que si no se enfatiza en el arte de comprender posiblemente tengamos más médicos y médicas, pero se salvarían menos vidas; tendríamos más arquitectos y arquitectas, pero también más familias sin hogar; tendríamos más economistas, pero menos acceso a los alimentos. En ese orden de ideas Freire (1979) destaca que "la educación como práctica de la libertad, al contrario de aquella que es práctica de la dominación, implica la negación del hombre abstracto, aislado, suelto, desligado del mundo, así como la negación del mundo como una realidad ausente de los hombres".

En relación con lo expuesto, debe impartirse una educación para la integración, para el trabajo, para la pertinencia social, económica y política del país, que destaque en la construcción colectiva de la sociedad necesaria y no para el individualismo y la explotación, enalteciendo no solo los derechos trascendentales de la humanidad, sino el deber de cumplirlos, una acción educativa del compromiso que hable del respeto, del amor, de la honestidad, de la búsqueda de la excelencia como norma ética de los ciudadanos y las ciudadanas, ya que, como refiere Maturana (1992), "el mundo en que vivimos es el mundo que nosotros configuramos y no un mundo que encontramos. El mundo en que vivimos lo configuramos en la convivencia, incluso cuando hablamos de lo interno y lo externo". 
Revista Universidad en Diálogo • Vol. 11, N. ${ }^{\circ}$ 1, Enero-Junio, 2021 • 11-35

ISSN 2215-2849 • EISSN: 2215-4752

URL: http://www.revistas.una.ac.cr/index.php/dialogo/index Correo ElECTRÓNICO: universidadendialogo@una.cr DOI: http://doi.org/10.15359/udre.11-1.1

Por ello, dicha educación debe centrarse en la pertinencia, debe tener carácter constructivo y productivo, ya que, en sintonía con Delors, no basta con aprender a conocer, sino que es necesario hacer. No obstante, dichas acciones no pueden ser creadas para perjudicar a otra persona o para sembrar tempestades, sino para enseñar a convivir en función de que dicho conocimiento y acciones puedan crear una ontología de la persona ciudadana necesaria. En función de lo planteado, el maestro Simón Rodríguez refiere que "no están por formar, sino por poner en práctica; pero no hay Resolución o no hay Constancia, y sin uno y otro no hay empresa" (1990).

En sintonía, para Carreño (2012):

Del ser y hacer del docente depende el proceso de formación integral de los estudiantes, que éstos adquieran una educación para la ciudadanía social practicando los valores morales, sociales, aprendiendo a vivir en comunidad. Sin embargo, algunos educadores suelen limitarse a proporcionar conocimientos e instrucciones, sin dedicarse a formarles como personas.

Lo esbozado surge de un conjunto de interrogantes que buscan develar no solo la pertinencia del tema, sino el acrecentamiento de su impacto, a fin de hacer una investigación de pertinencia educativa, social, política y económica, ya que la educación hace vida en diversos espacios de la sociedad y su impacto debe ser de trascendencia.

\section{El impacto de las estrategias didácticas aplicadas por docentes en Venezuela en el 2018}

Primeramente, y a modo de reflexión, es necesario destacar que en Venezuela, de acuerdo con la Constitución de la República Bolivariana de Venezuela, la educación es concebida como un derecho humano y un deber social fundamental. La educación es democrática, gratuita y obligatoria, exhortando al Estado a que la asuma como función indeclinable y de máximo interés en todos sus niveles y modalidades, y como instrumento del conocimiento científico, humanístico y tecnológico al servicio de la sociedad, destacando además que toda persona tiene derecho a una educación integral, de calidad, permanente, en igualdad de condiciones y oportunidades.

Sin embargo, de acuerdo con personas expertas, estas premisas esbozadas en la carta magna no se cumplen en su máxima expresión. Aunque el Estado pueda asumir el pago de las personas docentes, del personal administrativo y de los obreros y las obreras y la dotación de un morral para cada estudiante, 
URL: http://www.revistas.una.ac.cr/index.php/dialogo/index

CORREO ELECTRÓNICO: universidadendialogo@una.cr

DOI: http://doi.org/10.15359/udre.11-1.1

es insuficiente ante las necesidades básicas concernientes a la educación del presente y del futuro del país.

En este sentido, la Unesco (2007) plantea lo siguiente:

El acceso es una condición necesaria mas no suficiente para asegurar el derecho a la educación, ya que éste no garantiza por sí mismo que las personas construyan los aprendizajes relevantes esperados, ni que las experiencias educativas sean sensibles a las condiciones de las personas, lo que puede devenir en problemas serios de continuidad y conclusión de estudios, así como en limitaciones en los aprendizajes logrados.

El momento histórico educativo coincide estrechamente con lo planteado en párrafos anteriores, los problemas económicos que afectan al país inciden de manera significativa en el sistema educativo, iniciando con los efectos de la inflación venezolana, lo que sin duda repercute en el presupuesto para la inversión educativa, donde no solo se puede hablar de materiales didácticos, sino de infraestructura, productos de higiene, alimentación, implementos deportivos y recreativos, etc. A continuación, un ejemplo:

Los montos de salarios corresponden al sueldo básico; no se incluye bono de alimentación.

Tabla 1

Salarios de los docentes en América Latina

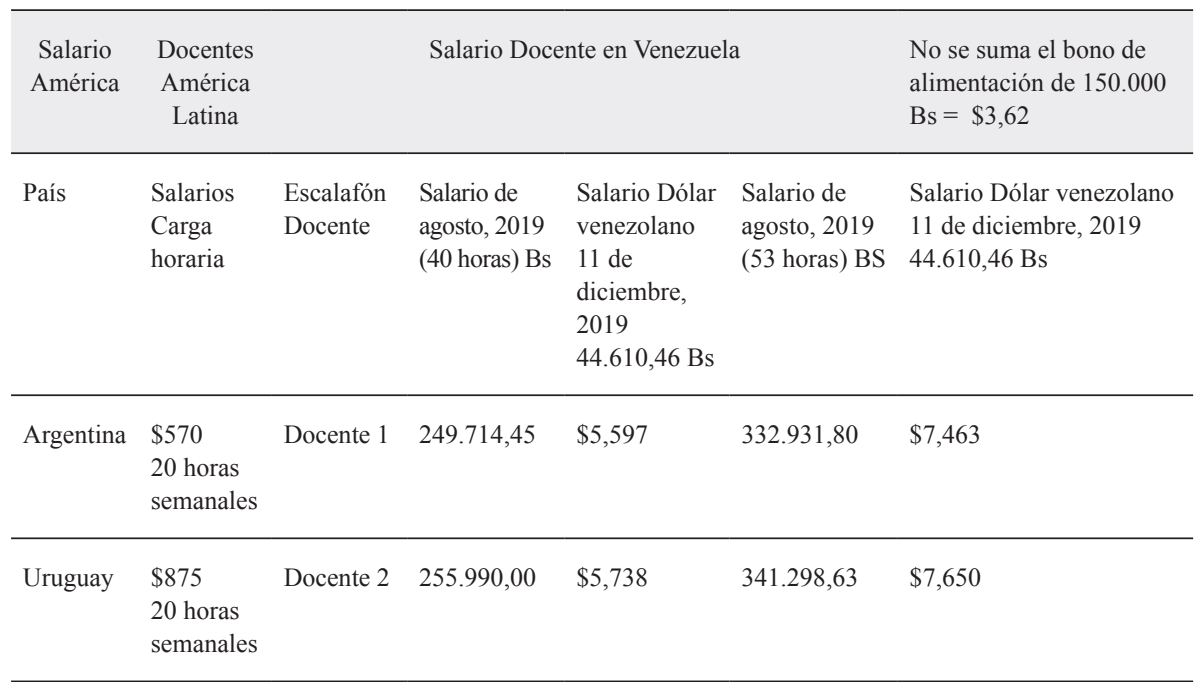


Revista Universidad en Diálogo • Vol. 11, N. ${ }^{\circ}$ 1, Enero-Junio, 2021 • 11-35

URL: http://www.revistas.una.ac.cr/index.php/dialogo/index CORREO ELECTRÓNICO: universidadendialogo@una.cr DOI: http://doi.org/10.15359/udre.11-1.1

\begin{tabular}{|c|c|c|c|c|c|c|}
\hline Salario & & \multicolumn{4}{|c|}{ Salario Docente en Venezuela } & \multirow{2}{*}{$\begin{array}{l}\text { No se suma el bono de } \\
\text { alimentación de } 150.000 \\
\text { Bs }=\$ 3,62\end{array}$} \\
\hline Brasil & $\begin{array}{l}\$ 737 \\
40 \text { horas } \\
\text { semanales }\end{array}$ & Docente 3 & $262.096,00$ & $\$ 5,875$ & $349.440,15$ & \\
\hline Chile & $\begin{array}{l}\$ 860 \\
35 \text { horas } \\
\text { semanales }\end{array}$ & Docente 4 & $270.756,00$ & $\$ 6,069$ & $360.985,48$ & $\$ 8,091$ \\
\hline Perú & $\begin{array}{l}\$ 516 \\
30 \text { horas } \\
\text { semanales }\end{array}$ & Docente 5 & $284.086,80$ & $\$ 6,368$ & $378.758,73$ & $\$ 8,490$ \\
\hline
\end{tabular}

Nota. Fuente sobre los salarios de los docentes en América Latina: Sputnik Mundo (2017) https://mundo. sputniknews.com/america-latina/201703081067436602-sueldos-america-latina-maestros/

Fuente sobre el tabulador del salario de los docentes en Venezuela (2019) https://www.trosell.net/news/ tabulador_oficial_docente ministerio_educacion_2019/2019-10-17-989

De la misma manera, la carencia de dinero en efectivo y para transporte incide en el ausentismo estudiantil y laboral. Además, los servicios públicos, como agua y luz, motivan la suspensión de clases, entre otros factores, como lo hace ver el Observatorio Educativo de Venezuela (2018):

En efecto, en Venezuela, en el último año, la educación ha experimentado una combinación compleja de problemas y impactos que alteraron la organización y el funcionamiento de las escuelas, teniendo como última consecuencia, restricciones en las garantías de varios derechos humanos, comenzando por el ejercicio del derecho a la educación, con la consecuente disminución en los logros y aprendizajes, durante el año escolar pasado.

En ese orden de ideas, el Diario Tal Cual (2018), en un reportaje titulado "Educación en Venezuela retrocede al siglo XIX", refiere que "unos tres millones de niños en Venezuela de tres a 17 años, asisten de forma irregular a la escuela o se ausentan de manera definitiva por fallas en el transporte, falta de comida u otras razones". Por más que se quisiera tildar dicha noticia como amarillismo o periodismo sensacionalista, es necesario entender que la educación no escapa de la realidad social, ya que forma parte de la sociedad. 
URL: http://www.revistas.una.ac.cr/index.php/dialogo/index

CORREO ELECTRÓNICO: universidadendialogo@una.cr

DOI: http://doi.org/10.15359/udre.11-1.1

Sobre lo anterior, Ander-Egg (1979 indica:

El problema de la educación no puede ser planteado aisladamente del contexto político, social, económico y cultural en que se da. Hoy es un lugar común de la sociología de la educación correlacionar la educación con el sistema social vigente. En todo país la educación responde o es reflejo del tipo de sociedad existente en el mismo.

En ese sentido, lo referido denota una fragmentación entre el Estado y la educación para el forjamiento de planes que venzan los desafíos presentes y los que están por venir. Si la didáctica implementada solo se centra en la enseñanza, y no es vigilante del tipo de aprendizaje que vislumbra o, como se planteara hace cien años en el manifiesto de Córdoba, "si no existe una vinculación espiritual entre el que enseña y el que aprende, toda enseñanza es hostil y por consiguiente infecunda", se seguirá incurriendo en las consecuencias educativas referidas por el Observatorio Educativo de Venezuela (2018):

1. Disminución de la capacidad de atención, concentración y aprendizaje por deficiencias en la alimentación, por problemas de salud y por los efectos de sufrir angustia psicosocial y los traumas psicológicos asociados a los impactos de las situaciones familiares y de seguridad. Los efectos físicos y psicológicos de la situación nacional afectan a los niños, niñas y jóvenes, más allá de sus consecuencias en el proceso de aprendizaje en las escuelas. En muchos casos la angustia se produce, directa o indirectamente, por la incertidumbre en la provisión de alimentos en el hogar, o porque se ven obligados a buscar empleo, a recurrir a la mendicidad o a hurgar en la basura, para conseguir alimentos y recursos.

En cuanto a los efectos físicos, es importante señalar que en diversas escuelas se registraron desmayos de estudiantes durante la realización de los actos cívicos al inicio de la jornada escolar, por deficiencias en la nutrición.

2. Inasistencias recurrentes, que agregan como factor adicional a la perturbación de la dinámica en las escuelas, la ruptura en la continuidad del proceso de aprendizaje y que tiene como consecuencia: la disminución del tiempo efectivo dedicado a las actividades escolares y la carencia de actividades estructuradas, restringiendo o disminuyendo la calidad de los procesos pedagógicos, y en consecuencia el alcance y la completitud de los aprendizajes. 
3. Disminución de las condiciones y recursos de las escuelas por fallas en los servicios, por hurtos y robos, por ausencia del personal docente calificado, lo que también restringe las oportunidades de contar con procesos pedagógicos de calidad por las deficiencias en las condiciones mencionadas.

4. Falta de recursos de los estudiantes para desarrollar actividades pedagógicas o tareas, fuera de las escuelas o en sus casas.

5. Disminución del tiempo escolar y de los aprendizajes relevantes por la incorporación de contenidos de baja calidad o no pertinentes, así como de incertidumbre y confusión por improvisación en las pautas curriculares y sus modificaciones y por suspensión innecesaria de actividades para la realización de elecciones y para la asistencia de miembros de las comunidades educativas a actividades político partidistas.

6. La combinación de estos efectos, tiene como última consecuencia la limitación del desarrollo pleno y de las oportunidades de desarrollo a futuro de los niños, niñas y jóvenes que es uno de los propósitos asociados a la realización del derecho a la educación.

De acuerdo a lo referido, no se puede transformar la educación si las propuestas de proyectos están enfocadas en asumir los problemas de forma y no la matriz del conflicto. Ahora bien, en correspondencia con lo planteado, ¿qué tan importante es la comprensión para las personas docentes y las personas estudiantes investigadoras a la hora de buscar nuevas alternativas para la praxis educativa, aún en momentos de crisis?

\section{La comprensión de las personas docentes y de las personas estudiantes investigadoras a la hora de buscar nuevas alternativas para la praxis educativa aún en momentos de crisis}

Ante la presencia de un mundo globalizado y contradictorio, donde se considera superada la sociedad de la información, dicotómicamente el ser humano tiene mayor acceso a internet, a la computadora, a los teléfonos inteligentes y a las redes sociales, pero desde el punto de vista comunicativo está más distanciado. En la sociedad del conocimiento, ante los grandes desafíos que transitan en el presente histórico, la humanidad no aprende a entenderse, a comprenderse, desde la diversidad para encontrar puntos comunes que permitan edificar un mundo mejor o en otros términos, como plantea Miguel Martínez (2013): 
"Habiendo entrado en el siglo XXI, muchos sectores de nuestra ciencia todavía no han entrado siquiera en el siglo XX"; esto amerita un proceso de renovación de nuestras didácticas educativas, con el fin de crear una educación más pertinente.

Al respecto, Savater (1997) señala lo siguiente: "Educar es creer en la perfectibilidad humana, en la capacidad innata de aprender y en el deseo de saber que la anima, en que hay cosas (símbolos, técnicas, valores, memorias, hechos...) que pueden ser sabidos y que merecen serlo, en que los hombres podemos mejorarnos unos a otros por medio del conocimiento".

Las didácticas aplicadas por las personas docentes deben responder a una educación de interés y pertinencia para la población estudiantil, ya que, como muchas personas expertas refieren, el educador o la educadora está contestando preguntas que el estudiantado no ha realizado, por consiguiente, esto, en vez de atraer, alejará a la persona estudiante, lo que puede disminuir su interés por la formación, al sentirse incomprendida o extraña en ese contexto que aparentemente busca prepararla.

En este sentido, Alvarado et al. (2018) indican lo expuesto a continuación:

En la Educación se deben construir ambientes afectivos, dinámicos, armoniosos y estimulantes, que permitan al estudiante socializar sus inquietudes, necesidades, intereses y deseos, en procura del enriquecimiento de sus vivencias y experiencias, bajo un clima favorable de libertad y asistencia pedagógica para el desarrollo del pensamiento creador y la generación del proceso de adquisición del lenguaje verbal y no verbal. De ahí, la necesidad de que sea acompañado desde los primeros instantes de su vida y durante el recorrido de su formación, de personas con capacidad de entrega y devoción educativa, permeadas constantemente por una disposición permanente hacia al amor como fuente de una buena convivencia desde lo ontoaxiológico.

Asimismo, Tedesco (2003) refiere que "el vínculo entre educación y cohesión ya no puede ser considerado simplemente como una aspiración conservadora y reproductora del orden social dominante". Por ello es necesario que la persona docente entienda la demanda del momento histórico en la búsqueda de alternativas didácticas, en consonancia con los tiempos presentes y los venideros.

Martínez (2004), en la búsqueda de esos métodos para la sostenibilidad social arraigados desde el humanismo, plantea lo siguiente: 
No se trata por consiguiente, de transmisión de información o conocimientos, ni de acrecentamiento del saber por acumulación, sino de crecimiento interior por un proceso de maduración que, abriendo nuevos horizontes y señalando nuevas perspectivas, va desarrollando integralmente la personalidad del estudiante.

Sin embargo, resulta un desafío bastante grande vencer esos viejos paradigmas, ya que se requiere la determinación de aceptar que hay que cambiar los viejos métodos que truncan el nacimiento de las nuevas técnicas necesarias.

En sintonía con lo expresado, Maturana (2001) refiere que "los educadores, a su vez, confirman el mundo que vivieron al ser educados en el educar".

Tal situación se puede deducir en los títulos de los trabajos especiales de grado, tanto de pregrado como de especialización y maestría, que hacen referencia a la necesidad de implementar estrategias didácticas para el logro de algún desafío formativo o en las expresiones de los y las estudiantes de Educación cuando refieren que lo aprendido en clase no se ajusta a la realidad o que la persona docente de aula no acepta la innovación de otros métodos. De igual manera, existe otro fenómeno que destacar: la fijación de las universidades en graduar lo más rápido posible al estudiantado, lo que propicia más una educación de competencia que con competencias.

En ese orden de ideas, Ercilia Vásquez (Granadillo, 2018), directora de la Escuela de Educación de la Universidad Católica Andrés Bello (UCAB), refiere lo expuesto a continuación:

La formación docente se ha tergiversado, se está dando formación en menos tiempo lo cual le resta calidad, y aunque la educación es un problema de todos, el docente es el núcleo y si su formación no es de calidad, la educación no va ser de calidad.

Ahora bien, la calidad educativa no se determina por la cantidad de años que dure la carrera, ya que, si no hay una tríada entre el contexto social, el educativo y las expectativas del o de la estudiante, la escolaridad se traducirá en un depósito de estudiantes. De la misma manera, la formación de los y las docentes - desde el contexto de la educación universitaria - debe estar a la altura del momento histórico, ya que su actuación repercutirá a futuro en los emprendimientos de sus estudiantes. 
URL: http://www.revistas.una.ac.cr/index.php/dialogo/index

CORREO ELECTRÓNICO: universidadendialogo@una.cr

DOI: http://doi.org/10.15359/udre.11-1.1

$\mathrm{Al}$ respecto, Ferguson y Lanz (2011) indican que

Entender las transformaciones universitarias como un proceso de cambio paradigmático en todos sus ámbitos, es decir, como una reforma del pensamiento, es la condición de posibilidad de transitar un camino de refundación del papel de la educación en esta nueva era planetaria.

Esta posición es respaldada por Vásquez (2018) en su experiencia como directora de la Escuela de Educación de la Universidad Católica Andrés Bello (UCAB), al interactuar con estudiantes de la carrera de Educación, que socializan las vivencias de las prácticas profesionales (pasantías) o su transitar en el mundo laboral:

Todo esto ha desvalorizado la profesión docente, porque se ha convertido al maestro en un seguidor de instrucciones, un imitador poco reflexivo, lo que ha llevado a desestimar su capacidad intelectual, considerándolo incapaz de tomar decisiones y de crear e innovar en el aula, esta situación y la falta de incentivos económicos hace que cada día nuestra carrera sea menos valorada, el prestigio del docente ha ido decayendo cada vez más y menos personas quieren estudiar esta carrera, sobre todo en instituciones donde no se les asegura empleo y las carreras tienen larga duración.

La estimulación juega un rol determinante en la actuación del ser humano en el contexto de la educación, bien sea en el ámbito laboral (ejercicio docente) o en el formativo (estudiantes de la carrera de Educación).

Según Chiavenato (2009):

La motivación es un proceso psicológico básico. Junto con la percepción, las actitudes, la personalidad y el aprendizaje, es uno de los elementos más importantes para comprender el comportamiento humano. Interactúa con otros procesos mediadores y con el entorno. Como ocurre con los procesos cognitivos, la motivación no se puede visualizar. Es un constructo hipotético que sirve para ayudarnos a comprender el comportamiento humano.

De acuerdo con los dos sujetos de estudios mencionados (estudiantes de Educación y personas educadoras), la motivación está regida por la teoría de las necesidades humanas, también conocida como Pirámide de Maslow. 
Revista Universidad en Diálogo • Vol. 11, N. ${ }^{\circ}$ 1, Enero-Junio, 2021 • 11-35

ISSN 2215-2849 • EISSN: 2215-4752

URL: http://www.revistas.una.ac.cr/index.php/dialogo/index CORREO ELECTRÓNICO: universidadendialogo@una.cr DOI: http://doi.org/10.15359/udre.11-1.1

Según Kremer y Hammond (2013),

En 1943, el psicólogo estadounidense Abraham Maslow publicó un ensayo llamado "Una teoría para la motivación humana", en el cual decía que las personas tenían - en un orden particular- cinco tipos de necesidades. En la medida que se satisface un nivel de necesidad, se activa el deseo de cumplir el siguiente.

Dichas necesidades se describen de la siguiente manera: 1 . Necesidad fisiológica (comer, dormir, esparcimiento, sexo, etc.). 2. Seguridad (estabilidad emocional, estabilidad económica, seguridad física, de empleo, de ingresos y recursos, familiar, de salud). 3. Afiliación (amor, afecto, la pertenencia o asociación a un cierto grupo social, familiar, etc.). 4. Reconocimiento (satisfacción, sentimiento de éxito, seguridad emocional, etc.).5.Autorrealización(sentimiento de felicidad, bienestar, comodidad, etc.). Dicha teoría está formulada mediante una estructura jerárquica de necesidades, las cuales deben cumplirse secuencialmente para llegar al éxito o autorrealización. En concordancia, García-Allen (2015) refiere:

Maslow proponía una teoría según la cual existe una jerarquía de las necesidades humanas, y defendió que, conforme se satisfacen las necesidades más básicas, los seres humanos desarrollamos necesidades y deseos más elevados. A partir de esta jerarquización se establece lo que se conoce como pirámide de Maslow.

\section{Jerarquía de las necesidades humanas}

En virtud de dar una mejor explicación de cómo dicha teoría influye en las acciones y los pensamientos de la ciudadanía venezolana, se presentan las cinco necesidades estructuradas en la pirámide de Abraham Maslow, utilizando como fuente el trabajo digital del psicólogo Jonathan García-Allen y un conjunto de inferencias por parte de quien le escribe, que denotan la influencia de la estructura creada por Maslow y su inherencia en la desmotivación social del Docente Venezolano.

\section{A. Necesidades fisiológicas}

Incluyen las necesidades vitales para la supervivencia y son de orden biológico. Dentro de este grupo encontramos necesidades como: respirar, beber agua, dormir, comer, de sexo, de refugio. Maslow piensa que estas necesidades son las más básicas en la jerarquía, ya que las demás necesidades son secundarias, hasta que no se hayan cubierto las de este nivel. 
Como ejemplo, se pueden anexar artículos de primera necesidad que condicionan parte de la rutina diaria de la persona ciudadana común, como productos para infantes e infantas (leche, pañales, medicamentos y vitaminas), que, si bien no forman parte de las necesidades directas del cuerpo docente, son fundamentales, ya que el educador o la educadora es un ser humano como cualquier habitante de esta sociedad.

Este es un factor emocional importante; las carencias o necesidades que puedan sufrir los hijos y las hijas de las personas docentes o que el estudiantado asista a la institución educativa sin haber desayunado afectan de forma significativa. También se puede mencionar la carencia de herramientas de trabajo, ya que, producto de la disminución en la dotación por parte del Estado, el encarecimiento de estas y el devaluado salario de las personas educadoras crean una situación de inestabilidad en dicho sujeto de estudio.

Posiblemente para algunas personas esta deducción sea un tanto exagerada, no obstante, es importante recordar que con la desaparición o disminución de los mencionados productos, además de herramientas, repuestos de vehículos particulares y cauchos, que obligan a la persona docente, ante la inhibición de utilizar su vehículo particular (para los y las que tienen), a utilizar medios de transporte no convencionales, como camiones y perreras, fomentan el desasosiego, la preocupación y el desequilibrio ya no solo en la persona, sino en su seno familiar. En este sentido, Chiavenato (2009) señala:

Una enorme variedad de factores motiva a los seres humanos. A una persona le puede gustar su trabajo porque satisface sus necesidades sociales y de seguridad. No obstante, las necesidades humanas siempre están cambiando. Lo que motiva a una persona hoy podría no estimularla mañana.

La mayoría de las personas que trabajamos en esta bella misión de educar, lo hacemos por vocación, estamos muy conscientes de que ninguna persona educadora se hará millonaria en el ejercicio de sus funciones, no obstante, no hay mayor recompensa que ver años después a los y las estudiantes y sentir que aportamos en el cumplimiento de sus metas. Posiblemente, esta conciencia inspiró a Freire (2004) en su trabajo titulado Pedagogía de la autonomía, al referir:

Soy profesor en favor de la lucha constante contra cualquier forma de discriminación, contra la dominación económica de los individuos o de las clases sociales. Soy profesor contra el orden capitalista vigente que inventó esta aberración; la miseria en la abundancia. Soy profesor en favor de la esperanza que me anima a pesar de todo. Soy profesor contra el desengaño que me consume y me inmoviliza. Soy profesor en favor 
de la belleza de mi propia práctica, belleza que se pierde si no cuido del saber que debo enseñar, si no peleo por este saber, si no lucho por las condiciones materiales necesarias sin las cuales mi cuerpo, descuidado, corre el riesgo de debilitarse y de ya no ser el testimonio que debe ser de luchador pertinaz, que se cansa pero no desiste.

Sin embargo, es necesario entender que la persona docente es de carne y hueso, es un ser humano, que siente, que padece, una persona que necesita sentirse querida, que necesita sentir que su esfuerzo es valorado y que esté dotada de las herramientas necesarias para el óptimo desarrollo de su didáctica; pero si no es tomada en cuenta por el Estado, el cual, de acuerdo con el artículo 103 de la Constitución de la República Bolivariana de Venezuela, debe realizar una inversión prioritaria, de conformidad con las recomendaciones de la Organización de las Naciones Unidas, así como crear y sostener a las instituciones y los servicios suficientemente dotados para asegurar el acceso, la permanencia y la culminación en el sistema educativo, toda aspiración de la persona docente culminará en una gran desesperanza, incidiendo esto en la calidad educativa.

\section{B. Necesidades de seguridad}

En esta parte de la pirámide de Maslow se incluyen las necesidades de seguridad necesarias para vivir, pero que están en un nivel diferente al de las necesidades fisiológicas. Es decir, hasta que las primeras no se satisfacen, no surge un segundo eslabón de necesidades que se oriente a la seguridad personal, al orden, a la estabilidad y la protección. Aquí figuran la seguridad física, de empleo, de ingresos y recursos, familiar, de salud, etc.

Juri (1995), citando a Morris Eagle (1995), afirma que "la seguridad se encuentra asociada con experiencias de bienestar que acompañan el cuidado del apegado, incluidas las regulaciones homeostáticas y las gratificaciones provistas por la madre". Ahora bien, en relación con el sentimiento de seguridad es importante denotar en ese orden de ideas lo que señala Díaz (2013):

La percepción de la inseguridad se compone de un factor objetivo y un subjetivo. El componente objetivo se puede definir como la inseguridad real existente en la comunidad. Se le ha definido, como un complejo entramado de actitudes que otorgan una idea de la situación que guardan las posibilidades particulares de un individuo de ser victimizado o el riesgo que corre al estar en lugares y situaciones consideradas por él, como peligrosas y la posición en la que se ubica el sujeto respecto a su entorno independientemente de las condiciones delictivas reales. 
Mucho se habla del ausentismo laboral parcial o permanente en el contexto escolar, por parte, en gran medida, de las personas docentes. Entre los motivos se encuentran reposos médicos, incapacitaciones, renuncias por inconformidades con las condiciones laborales, emigración a otros países, años sabáticos, entre otros, lo que sin duda, de acuerdo con la disminución de la satisfacción de las necesidades básicas de la persona docente y el sentimiento de inseguridad, no solo afecta la educación en Venezuela, bien sea por la calidad de las estrategias didácticas o las constantes interrupciones académicas, sino que es una realidad que no se puede invisibilizar.

En correspondencia, Castillo (2018) refiere que "esta dura realidad ha producido la deserción de miles de profesionales, quienes han abandonado las aulas para dedicarse a otras tareas o han emigrado al exterior en busca de mejores oportunidades".

El sentimiento de seguridad se convierte en un factor determinante en la actuación de la persona docente, generando preocupación, depresión y desesperanza, lo que sin duda incide en tomar decisiones no tan convenientes, como la venta de activos personales, endeudamientos, solicitud de falsos reposos para la dedicación de otras actividades económicas, renuncia, falta a la ética docente, ventas de notas, hurto de material escolar.

Yuncoza (2017) señala lo siguiente:

Si reflexionamos sobre la teoría de Maslow, podemos concluir que el ciudadano en Venezuela ha dejado a un lado cualquier otra consideración que le haga sentirse un individuo pleno, a cambio de cubrir las necesidades que le permitan sobrevivir como ser vivo. Si para ello debe incurrir en actividades delictivas, pareciera que eso queda en segundo plano. Lo importante para algunos es el aquí y el ahora. Uno de los costos más importantes de dicho comportamiento, es el modelaje negativo que se refleja en los jóvenes que tomarán como normal y necesaria, dicha alternativa de actuación.

Es importante afirmar que en ningún momento se busca dar una imagen de la persona docente como un sujeto de mentalidad reduccionista ante las situaciones adversas, por el contrario, se busca hacer referencia de esta persona educadora como un sujeto social víctima de las consecuencias generadas por la presente crisis económica y ciudadana que vive el país. En sintonía, para José Javier Salas (2018), docente de la Universidad Católica Andrés Bello (UCAB): 
El educador, al igual que el resto de los profesionales de este país, sufre las consecuencias de un proceso inflacionario sin precedentes. El hecho es claro, no hay incremento de sueldo que resista la pérdida del poder adquisitivo del Bolívar. Pero en el caso del docente el escenario es aún más preocupante.

Como se puede ver, la motivación incide significativamente en el emprendimiento de la tarea diaria del maestro y de la maestra. En muchos casos se pretende arrojar toda la responsabilidad a la persona docente, olvidando que la educación no solo refiere al contexto escolar, sino que hay dos miradas que también son inherentes, la educación no formal y la denominada informal, donde la familia juega un rol determinante.

Mujica (2014) refiere: "No le pidamos al docente que arregle los agujeros que hay en el hogar". En otros casos, aunque un poco más deferente, pero todavía de manera injusta, se le sigue acarreando toda la responsabilidad, se le tilda de héroe sin capa, alejándolo de su condición de humano y ser imperfecto.

Sin embargo, como planteó Savater (1997):

Todos tenemos miedos y recelos, sentimos desánimo e impotencia y por eso la profesión de maestro en el más amplio sentido del noble término, en el más humilde también - es la tarea más sujeta a quiebras psicológicas, a depresiones, a desalentada fatiga acompañada por la sensación de sufrir abandono en una sociedad exigente pero desorientada.

\section{Necesidades de afiliación}

Maslow describe estas necesidades como menos básicas y tienen sentido cuando las necesidades anteriores están satisfechas. Ejemplos de estas necesidades son: el amor, el afecto y la pertenencia o afiliación a un cierto grupo social, que buscan superar los sentimientos de soledad. Estas necesidades se presentan continuamente en la vida diaria, cuando el ser humano muestra deseos de casarse, de tener una familia, de ser parte de una comunidad, ser miembro de una iglesia o asistir a un club social.

Una de las grandes preocupaciones del ser humano durante varias generaciones es ser aceptado, posiblemente de allí se desprende la apetencia por bienes materiales, la aspiración a diversos estilos de vida, el amoldamiento a dogmas coyunturales, las costumbres y los comportamientos, generados por un 
significativo sentimiento de inseguridad que los hace buscar opciones para sentirse aceptados en grupos y/o espacios específicos. En ese orden de ideas, Maturana (1992) deduce lo siguiente:

Vivimos en una cultura centrada en la apropiación, vivimos de la apropiación, y en ella aprendemos a querer, a desear y a necesitar cosas que nos son en lo fundamental superfluas, pero dependemos de ellas, de modo que si no se nos dan vivimos en la escasez.

Este autor destaca la necesidad de amor, de afecto, de reconocimiento de nuestro esfuerzo y de pertenencia o afiliación a un grupo social, aspectos que buscan superar los sentimientos de soledad. Para Hevia et al. (2006) son "las necesidades de amor y pertenencia que están orientadas socialmente y representan la voluntad de reconocer y ser reconocido por los semejantes".

Hoy, producto de la crisis socioeconómica que vive Venezuela, la persona docente se siente muy vulnerable al no ser reconocida su labor, denotándose en la actuación del Estado, que ha colocado al gremio educativo como uno de los sectores con los niveles más altos de desatención. Esto repercute en la disminución de la calidad de vida de los y las profesionales de la educación e incide en el diseño de las estrategias didácticas aplicadas para la formación de niños, niñas, adolescentes y personas adultas.

\section{Necesidades de reconocimiento}

Tras cubrir las necesidades de los tres primeros niveles de la pirámide de Maslow, aparecen las necesidades de reconocimiento, como la autoestima, el reconocimiento hacia la propia persona, el logro particular y el respeto hacia las demás personas. Al satisfacer dichas necesidades, la persona se siente segura de sí misma y piensa que es valiosa dentro de la sociedad; cuando estas necesidades no son satisfechas, las personas se sienten inferiores y sin valor.

En esta escala Maslow se refiere a la autoestima, que se traduce en la autodeterminación de la persona, o en el autoconcepto que cada persona tiene de sí misma. En las tres escalas anteriores se observó cómo la vulneración de las necesidades fisiológicas o el cambio brusco del confort a la austeridad influye en el aspecto emocional del ser humano, así como también en su comportamiento con la sociedad. En ese sentido, García-Allen (2015) refiere que esa necesidad de reconocimiento, o autoestima, requiere una serie de aristas para la concreción del mismo: 
Según Maslow existen dos necesidades de reconocimiento: una inferior, que incluye el respeto de los demás, la necesidad de estatus, fama, gloria, reconocimiento, atención, reputación, y dignidad; y otra superior, que determina la necesidad de respeto de sí mismo, incluyendo sentimientos como autoconfianza, competencia, logro, independencia y libertad.

No obstante, al estar inmerso en una (¿porque no decirlo?) crisis emocional debido a la disminución del cumplimiento de sus necesidades básicas, el alejamiento del clima de seguridad y la distorsión de las relaciones humanas quebrantan la garantía de que la persona pueda tener una alta autoestima y una salida proactiva a su situación, producto del hostigamiento físico y mental al que está sometido producto de las circunstancias.

En concordancia, Ovejero (2007) refiere lo siguiente:

El mundo social que nos rodea es muy complejo y con frecuencia imprevisible. Sin embargo, la gente necesita entender lo que acontece a su alrededor como forma de conseguir una adecuada adaptación al medio y sacar de él el máximo partido posible.

El actual clima de incertidumbre que vive la persona docente, producto de la depreciación de su nivel de ingreso o de su poder adquisitivo, y la devaluación de las relaciones sociales, sin duda alguna, repercuten en una serie de deterioros en las relaciones humanas, quiebres en las relaciones de pareja, discordias en vínculos profesionales, de amistad o familiares, de acuerdo con la devaluación de componentes axiológicos, como el reconocimiento, el respeto a las demás personas, atención, reputación, dignidad, autoconfianza, competencia, logro, independencia y libertad, producto del momento histórico en que se vive, generando una reacción de causa y efecto.

En sinergia, Goleman (2000) plantea que "para un desempeño estelar en todos los trabajos, en todas las especialidades, la aptitud emocional es dos veces más importante que las facultades puramente cognitivas". Lo que denota que, ante la actual coyuntura, la desmotivación de la persona docente juega un papel fundamental en el fracaso de las estrategias didácticas aplicadas en cualquier nivel o contexto educativo.

\section{E. Necesidades de autorrealización}

"Por último, en el nivel más alto se encuentran las necesidades de autorrealización y el desarrollo de las necesidades internas, el desarrollo espiritual, 
moral, la búsqueda de una misión en la vida, la ayuda desinteresada hacia los demás, etc." Desde una perspectiva normal de esta teoría se podría concluir que es una recompensa o el logro del objetivo planteado; no obstante, mediante el análisis del conflicto o inverso puede identificarse como la consecuencia de los vacíos referentes a las necesidades fisiológicas, al sentimiento de seguridad, a la afiliación y a la autoestima, lo que resulta en desesperanza, frustración, y/o destrucción moral de una persona, al enfocarse más en los aspectos del fracaso que en las oportunidades de revertirlo.

Maturana (1992) señala:

Si uno vive al borde de la escasez, no puede salirse de la confrontación continua con el otro, pero si uno coopera con el otro en la conciencia de que el mundo que viven lo hacen en común, y si uno y otro se respetan, se puede salir de la escasez porque se puede entrar en la conspiración que lleve a la estabilización de la población.

\section{Una nueva visión de la investigación educativa}

Ahorabien, antelo expuesto, sin duda alguna, hace falta quenuestras investigaciones en el campo de la educación sean congruentes con una humanización con los seres humanos y, por consiguiente, para los seres humanos, y por supuesto sin invisibilizarlos con propuestas para el mejoramiento del aprendizaje - a través de la praxis de la persona docente- donde no se entienda su condición de sujetos.

Backes et al. (2007) refieren lo expuesto a continuación:

Las reflexiones filosóficas en el campo de la humanización vienen adquiriendo gran importancia, principalmente, frente al principio de responsabilidad científica y social y de la aparente impotencia ética frente a un ser humano tecnológico, capaz de organizar, desorganizar y cambiar radicalmente, los fundamentos de la vida, es decir, de crear y/o destruirse a sí mismo.

En ese orden de ideas, las instituciones de formación profesional docente deben asumir su responsabilidad social ante la persona profesional que forman para el país. No podemos exigir que el personal docente esté a la altura del momento histórico si nuestros pénsum son del siglo XX, ni mucho menos exigir personas profesionales innovadoras si la libertad de cátedra y el pensamiento crítico son un delito dentro de estas instituciones. 
Zemelman (2006) afirma:

Si no estamos construyendo un pensamiento teórico porque no estamos comprendiendo los fenómenos de nuestras realidades, con toda su carga histórica y la propia historicidad del fenómeno ¿Cómo podemos formar a la gente joven? ¿Cómo se puede formar a alguien, en el sentido de enseñarle a pensar?

\section{Las nuevas alternativas deben buscarse para la praxis educativa de los y las docentes aún en momentos de crisis}

Hablar de las estrategias más idóneas para la praxis educativa como si se tratara de una receta genérica aplicada a objetos y no a sujetos sociales, particularmente identificados con diversas corrientes de pensamiento, sería una gran farsa.

Por décadas, los currículos han impuesto una historia que no es la nuestra, unas costumbres que, aunque no nos identifican, se establecen como la única alternativa y, por supuesto, vivir en una realidad que no es la nuestra. Estas imposiciones forjadas en cuatro paredes, y que responden más al poder que al empoderamiento colectivo, hacen a una dirigencia analfabeta de la realidad social.

Zemelman (2006) destaca que

Hoy en día volvemos a estar al frente de una intelectualidad que no ve la realidad, para la cual no existe esa realidad. Existe la realidad del discurso del poder tal como en ese momento existió la realidad que imponía el discurso de poder de esa época.

En tal sentido, no se puede hablar de educación sin relacionarla con la realidad social, ya que esta no sería de pertinencia y, por consiguiente, sería improductiva. Al respecto, Maturana (2001) plantea que "uno no puede reflexionar acerca de la educación sin hacerlo antes o simultáneamente acerca de esta cosa tan fundamental en el vivir cotidiano como es el proyecto de país en el cual están inmersas nuestras reflexiones sobre educación". Si no se entiende esta (la educación) como un proceso ontoepistémico en el que se pueda combinar el conocimiento con la conciencia, la educación no podrá cumplir con su fin transformador; por el contrario, se seguirán implementando los métodos tradicionales, que reproducen un saber heredado incomprendido y no construido. 
URL: http://www.revistas.una.ac.cr/index.php/dialogo/index

CORREO ELECTRÓNICO: universidadendialogo@una.cr

DOI: http://doi.org/10.15359/udre.11-1.1

Tineo (2018), al respecto, señala lo siguiente:

La Investigación Educativa desde un pensamiento Ontoepistemológico, nos permite evaluar el pensamiento del otro con nuestra propia argumentación, es decir, se establece un pensamiento dialógico que irradia explicación de aceptación de las opiniones del otro, pero también se puede contradecir conceptos con argumentos que evidencie nuestra diferencia opinática.

En razón de ello, la educación debe centrarse en las necesidades de la humanidad y no en la conveniencia de los grupos de poder, sean económicos, políticos o comunicacionales, entre otros. Debe romperse con el tradicional dogma de que educar en valores, con conciencia ecológica y humanista es una pérdida de tiempo. Por el contrario, la educación que hoy enseña a competir está detrás de los grandes problemas que tenemos como sociedad, en razón de ello el maestro Cruz Diez (Diario Panorama, 2017) refiere lo siguiente:

Hay que inventar un nuevo lenguaje político que hable de democracia, de valores éticos, de libertad, progreso y justicia social, hay que inventar la educación y crear un país de emprendedores, artistas e inventores, un país digno y soberano en el contexto global, en fin, en Venezuela hay que inventarlo todo ¡Qué maravilla!

En diversos trabajos donde se expone este tipo de tema se habla de la necesidad de una persona docente reflexiva, crítica, proactiva, integradora, irreverente, sin embargo, es necesario considerar dos aspectos, primero, ese prototipo de docente no llegará de la nada, requiere formación, y segundo, no podemos esperar una persona docente distinta si formamos con los mismos métodos. Por ello, como plantea Vázquez (2018), "por tanto se trata de un cambio más profundo, de un cambio paradigmático; es decir un cambio en la forma de percibir la realidad, en las creencias, actitudes y valores para facilitar el cambio que necesitamos".

\section{Conclusión}

Se reconoce la pertinencia de que nuestro estudiantado de pregrado denote la necesidad de realizar sus objetos de estudio referentes a las estrategias didácticas que debe aplicar el personal docente en diversos espacios del proceso de enseñanza y aprendizaje. No obstante, no se puede hablar de educación deshumanizándola, sin entender que tanto la persona docente como el y la estudiante son sujetos y no objetos. 
Gutiérrez (1974) afirma: "Estamos educando gente para que responda a preguntas que ya han sido formuladas -que es lo que también hacen las computadoras en lugar de enseñarles a formular nuevas preguntas".

Desde la formación para personas formadoras o, en otros términos, desde las escuelas de educación, debe entenderse la compleja situación de resistencia en la que nos encontramos las personas que soñamos con la construcción de un mundo distinto desde las aulas y la necesidad de formar nuevos y nuevas combatientes para no perder esa gran batalla con la desatención estatal.

Para muchas personas esta posición puede sonar fabulosa, pero, como plantean Morin y Delgado (2014), "no abogamos por una esperanza ilusoria y salvadora, sino por una utópica y creadora, activadora y regeneradora, que se corresponde con el momento en que vivimos, que es el momento de actuar".

\section{Referencias}

Ander, E. (1979). Hacia una pedagogía autogestionaria. Buenos Aires, Argentina: El Cid Editor.

Alvarado, B., Meléndez, D., Torrealba, M. y Plana, P. (2018). Ontoaxiología educativa desde la pedagogía del amor. CIEG. http://www.grupocieg. org/archivos revista/Ed.\%2033\%20(180-189)-Alvarado\%20BelkisMel\%C3\%A9ndez\%20Daisy-Torrealba\%20Manuel-Plana\%20Petra articulo id397.pdf

Carreño, A. (2012). El ser y el hacer del docente venezolano en el contexto de la educación bolivariana: paradigmas y realidades (tesis doctoral). Universidad de Carabobo Valencia Edo. Carabobo.

Castillo, E. (2018). "2018 es un año decisivo para los docentes": habla el director de la Escuela de Educación de la UCAB. Entrevista al director de la Escuela de Educación de la Universidad Católica Andrés Bello. Portal Web elucabista.com. http://elucabista.com/2018/01/10/2018-es-un-ano-decisivopara-los-docentes-habla-el-director-de-la-escuela-de-educacion-de-la-ucab/

Chiavenato, I. (2009). Comportamiento-organizacional. México, D.F: McGraw-Hill/Interamericana Editores.

Delors, J. (1994). La Educación Encierra un Tesoro. Informe a la Unesco de la Comisión Internacional sobre la Educación para el Siglo XXI. 
Diario Tal Cual claro y raspao. (25 de abril de 2018). Educación en Venezuela retrocede al siglo XIX. http://talcualdigital.com/index.php/2018/04/25/ educacion-en-venezuela-retrocede-al-siglo-xix-segun-experto/

Díaz, G. (2013). Factores psicológicos de la percepción de inseguridad. Revista Iberoamericana para la Investigación y el Desarrollo Educativo. http://ride.org.mx/1-11/index.php/RIDESECUNDARIO/ article/viewFile/330/322

Diario Panorama. (2017). La carta que el artista plástico Carlos Cruz-Diez envió a los venezolanos. https://www.panorama.com.ve/espectaculos/ La-carta-que-el-artista-plastico-Carlos-Cruz-Diez-envio-a-losvenezolanos-20170428-0116.html Publicada 28/04/2017

Ferguson, A. y Lanz, R. (2011). La transformación universitaria y la relación universidad-estado-mundo. Observatorio Internacional de Reformas Universitarias ORUS-VE.

Freire, P. (1979). Pedagogía del oprimido. España: Siglo Veintiuno Editores.

Freire, P. (2004). Pedagogía de la autonomía. Sao Paulo, Brasil: Editorial Paz e Tierra.

García-Allen (2015). Pirámide de Maslow: la jerarquía de las necesidades humanas. https://psicologiaymente.net/psicologia/piramide-de-maslow

Goleman, D. (2000). La inteligencia emocional en la empresa. Argentina: Ediciones Vergara.

Granadillo, A. (2018). Proyección de la educación en Venezuela. Entrevista a Ercilia Vásquez. Directora de la Escuela de Educación de la Universidad Católica Andrés Bello (UCAB). http://w2.ucab.edu.ve/proyeccion-dela-educacion-en-venezuela.html

Gutiérrez, F. (1974). Pedagogía de la comunicación. San José, Costa Rica: Editorial Costa Rica.

Juri, L. J. (1995). El sentimiento de seguridad es un camino del desarrollo. Psicofisiología - UNR. http://www.psicofisiologia.com.ar/index. php?option=com_content\&task=view\&id $=231 \&$ Itemid $=53$ 
Revista Universidad en Diálogo • Vol. 11, N. ${ }^{\circ}$ 1, Enero-Junio, 2021 • 11-35

ISSN 2215-2849 • EISSN: 2215-4752

URL: http://www.revistas.una.ac.cr/index.php/dialogo/index CORREO ElECTRÓNICO: universidadendialogo@una.cr DOI: http://doi.org/10.15359/udre.11-1.1

Kremer, W. y Hammond, C. (2013). ¿Qué tan correcta es la pirámide de Maslow? BBC Mundo http://www.bbc.com/mundo/ noticias/2013/09/130902 salud piramide maslow aniversario gtg

Maturana, H. (1992). El sentido de lo humano. Santiago, Chile: Ediciones Pedagógicas Chilenas.

Martínez, M. (2004). La psicología humanista; un nuevo paradigma psicológico. México: Editorial Trillas.

Martínez, M. (2013). La investigación cualitativa etnográfica en educación. Caracas, Venezuela: Editorial Trillas.

Morin, E. y Delgado, C. (2014). Reinventar la educación: hacia una metamorfosis de la humanidad. Multiversidad Mundo Real Edgar Morin, México.

Mujica, J. (2014). No le pidamos al docente que arregle los agujeros que hay en el hogar. Presidencia de la República Oriental del Uruguay. https://www.presidencia.gub.uy/comunicacion/comunicacionnoticias/ utu-colonia-nicolich-mujica-inauguracion

Observatorio Educativo de Venezuela. (2018). Monitoreando el cumplimiento del derecho a la educación en Venezuela. https://observatorioeducativo. wordpress.com/2018/09/10/hay-condiciones-para-el-inicio-del-anoescolar-2018-2019-el-proximo-17-de-septiembre-en-venezuela/

Ovejero, A. (2007). Las relaciones humanas. Psicología social teórica y aplicada. Madrid, España: Editorial Biblioteca Nueva. https://es.scribd. com/doc/49974809/LAS-RELACIONES-HUMANAS

Reforma de Córdoba. (1918). http://www.saber.ula.ve/bitstream/ handle/123456789/22014/articulo2.pdf?sequence=1

Savater, F. (1997). El valor de educar. Barcelona, España: Editorial Ariel.

Stein, D., Santos, M. y Lorenzini, A. (2007). Humanizando el cuidado a través de la valorización del ser humano: resignificación de los valores y principios por los profesionales de salud Revista LatinoAmericana de Enfermagem, 15(1), 34-41. https://dx.doi.org/10.1590/ S0104-11692007000100006 
URL: http://www.revistas.una.ac.cr/index.php/dialogo/index

CORREO ELECTRÓNICO: universidadendialogo@una.cr

DOI: http://doi.org/10.15359/udre.11-1.1

Rodríguez, S. (1990). Sociedades americanas. Caracas, Venezuela: Biblioteca Ayacucho.

Tineo, L. (2018). Investigación educativa desde la ontoepistemología. Revista Vinculando. http://vinculando.org/educacion/investigacion-educativadesde-la-ontoepistemologia.html

Yuncoza, A. (28 de marzo de 2017). Venezuela, Maslow y la seguridad. El Universal. http://www.eluniversal.com/noticias/opinion/ venezuela-maslow-seguridad 645582

Zemelman, H. (2006). El conocimiento como desafío posible. Instituto Politécnico Nacional, México D. F. 